\title{
Metabotropic Glutamate Receptors in Glial Cells: A New Potential Target for Neuroprotection?
}

\section{Simona Federica Spampinato', Agata Copani2,3, Ferdinando Nicoletti ${ }^{4,5}$, Maria Angela Sortino ${ }^{1 t}$ and Filippo Caraci ${ }^{2,6 * t}$}

\begin{abstract}
${ }^{1}$ Department of Biomedical and Biotechnological Sciences, University of Catania, Catania, Italy, ${ }^{2}$ Department of Drug Sciences, University of Catania, Catania, Italy, ${ }^{3}$ Institute of Biostructure and Bioimaging, National Research Council, Catania, Italy, ${ }^{4}$ Department of Physiology and Pharmacology, Sapienza University of Rome, Rome, Italy, ${ }^{5}$ Neuromed, Istituto di Ricovero e Cura a Carattere Scientifico, Pozzilli, Italy, ${ }^{6}$ Oasi Research Institute, Istituto di Ricovero e Cura a Carattere Scientifico, Troina, Italy
\end{abstract}

Neurodegenerative disorders are characterized by excitotoxicity and neuroinflammation that finally lead to slow neuronal degeneration and death. Although neurons are the principal target, glial cells are important players as they contribute by either exacerbating or dampening the events that lead to neuroinflammation and neuronal damage. A dysfunction of the glutamatergic system is a common event in the pathophysiology of these diseases. Metabotropic glutamate (mGlu) receptors belong to a large family of $G$ protein-coupled receptors largely expressed in neurons as well as in glial cells. They often appear overexpressed in areas involved in neurodegeneration, where they can modulate glutamatergic transmission. Of note, mGlu receptor upregulation may involve microglia or, even more frequently, astrocytes, where their activation causes release of factors potentially able to influence neuronal death. The expression of mGlu receptors has been also reported on oligodendrocytes, a glial cell type specifically involved in the development of multiple sclerosis. Here we will provide a general overview on the possible involvement of mGlu receptors expressed on glial cells in the pathogenesis of different neurodegenerative disorders and the potential use of subtype-selective mGlu receptor ligands as candidate drugs for the treatment of neurodegenerative disorders. Negative allosteric modulators (NAM) of mGlu5 receptors might represent a relevant pharmacological tool to develop new neuroprotective strategies in these diseases. Recent evidence suggests that targeting astrocytes and microglia with positive allosteric modulators (PAM) of mGlu3 receptor or oligodendrocytes with mGlu4 PAMS might represent novel pharmacological approaches for the treatment of neurodegenerative disorders.

\section{Keywords: neurodegeneration, metabotropic glutamate receptor, transforming growth factor- $\beta 1$, apoptosis,} neuroprotection

\section{INTRODUCTION}

Neurodegenerative disorders, among the most prevalent, devastating and yet poorly treated illnesses are progressive diseases characterized by slow neuronal death. Dysfunction of glutamatergic transmission plays a central role in the pathogenesis of neurodegenerative diseases (Nguyen et al., 2011). Malfunctioning or aberrant expression of glutamate transporters leads in fact 
to the accumulation of this neurotransmitter followed by overactivation of ionotropic glutamate receptors, mainly NMDA receptors, a primary event in the pathophysiology of neuronal damage. Activation of NMDA and/or AMPA receptor lacking the GluR2 subunit (Dugan and Choi, 1994; Zipfel et al., 2000), leads to an excessive influx of extracellular $\mathrm{Ca}^{++}$that triggers a cascade of events leading to apoptotic and necrotic death. This occurs both in acute and chronic neurodegenerative conditions such as AD, ischemia, ALS (Doble, 1999; Hardingham and Bading, 2003).

The underlying context is a condition of neuroinflammation, defined as an innate immunological response of the nervous system, involving glial cells, microglia, astrocytes, and cytokines, chemokines, ROS, and other factors they release (Kim and de Vellis, 2005; Block and Hong, 2007; Benatti et al., 2016). Excitotoxicity and neuroinflammation are strictly interconnected since increased extracellular levels of glutamate critically favor activation of glial cells and promotion of neuroinflammatory phenomena in the brain (Olmos and Llado, 2014). In this scenario, glial cells (astrocytes, microglia, and oligodendrocytes) reciprocally interact to contribute to the pathophysiology of neurodegeneration. Under physiological conditions, astrocytes play a key role in the homeostatic control of CNS environment, by removing glutamate from the extracellular space through specific transporters, GLAST and GLT1 (Oliet et al., 2001), as well as by controlling formation (Ullian et al., 2001) and pruning of synapses in response to changes of neuronal activity (Stevens et al., 2007). Dysfunction of astrocytes causes glutamate accumulation with ensuing excitotoxicity (Werner et al., 2001). Reactive astrocytes can further precipitate neuroinflammation (Verite et al., 2018) through the release of pro-inflammatory cytokines and chemokines, including CCL2, which recruits peripheral monocytes into the CNS. Accordingly, apoptotic astrocytes and reactive astrogliosis critically contribute to neurodegenerative processes in different forms of dementia (Heneka et al., 2010) including AD (Kobayashi et al., 2002), vascular (Tomimoto et al., 1997), and frontotemporal dementia (Martin, 2000).

Microglial cells are professional phagocytes (Gomez-Nicola and Perry, 2015) that regulate synapses pruning (Schafer et al., 2012) and phagocytosis of cells undergoing programmed death, both during development and in the mature healthy brain. They also support immune surveillance in the CNS (Zabel and Kirsch,

\footnotetext{
Abbreviations: 6-OHDA, 6-hydroxydopamine; AD, Alzheimer disease; AMPA, $\alpha$-amino-3-hydroxy-5-methyl-4-isoxazolepropionic receptor; ASL, amyotrophic lateral sclerosis; $\mathrm{A} \beta$, beta amyloid; $\mathrm{BBB}$, blood brain barrier; BDNF, brain derived neurotrophic factor; CHPG, (RS)-2-chloro-5-hydroxyphenylglycine; CCL2, monocyte chemoattractant protein-1; CNS, central nervous system; DHPG, (S)-3,5-dihydroxyphenylglycine; EGF, epidermal growth factor; FGF, fibroblast growth factor; GalC+, galactocerebroside; GLAST, L-glutamate/Laspartate transporter; GLT-1, glutamate transporter-1; IL-6, interleukin 6; JNK, c-Jun N-terminal kinase; L-AP4, L-(+)-2-amino-4-phosphonobutyric acid; LPS, lipopolysaccharide; LTP, long term potentiation; MBP, myelin basic protein; mGlu, metabotropic glutamate receptor; MPEP, 2-methyl-6-(phenylethynyl)pyridine; MS, Multiple sclerosis; NAM, negative allosteric modulator; NMDA, $N$-methyl-Daspartate receptor; NMO, neuromyelitis optica; OGD, oxygen glucose deprivation; OPC, oligodendrocytes progenitor cell; PAM, positive allosteric modulator; PD, Parkinson disease; PI3K, phosphatidylinositol-3-kinase; ROS, reactive oxygen species; sAPP $\alpha$, soluble amyloid precursor protein; SCI, spinal cord injury; SOD-1, superoxide dismutase; TBI, traumatic brain injury; TGF- $\beta 1$, transforming growth factor $\beta 1$; TNF $\alpha$, tumor necrosis factor $\alpha$; TrkB, tyrosin receptor kinase $B$.
}

2013). In response to a prolonged inflammatory stimulus or to the accumulation of misfolded proteins, such as aggregated $A \beta$, $\alpha$-synuclein, mutant huntingtin, SOD1, hyperactivated microglia can amplify neurodegeneration, by releasing pro-inflammatory cytokines (Block and Hong, 2007; Mosher and Wyss-Coray, 2014; Streit and Xue, 2014) and ROS (Wilkinson and Landreth, 2006; Dewapriya et al., 2013). Microglia also strongly influence glutamatergic transmission by regulating the expression of glutamate receptors and transporters in neighbor cells (Aronica et al., 2005a; Pickering et al., 2005; Tilleux et al., 2007). Increased extracellular levels of glutamate under pathological conditions, induce microglia chemotaxis to the injury site, through activation of both ionotropic and mGlu receptors expressed in microglia cells (Liu et al., 2009).

In addition to astrocytes and microglia, oligodendrocytes have an essential role in maintaining CNS homeostasis by supporting neuronal myelination and protecting axonal membrane (Rosenbluth, 2009; Bakiri et al., 2011; Harris and Attwell, 2012). Oligodendrocyte dysfunction is mainly involved in the pathogenesis of classical demyelinating diseases (MS and NMO) and leukodystrophies (Fellner and Stefanova, 2013; Ettle et al., 2016). Recent studies suggest that ischemic insults, trauma, and accumulation of abnormal protein aggregates (i.e., $\alpha$-synuclein, tau, PrP) also cause oligodendrocytes malfunction, leading to myelin disruption and thus neuronal conduction impairment, as reviewed in Ferrer (2018).

\section{mGlu RECEPTORS IN GLIAL CELLS: DISTRIBUTION AND FUNCTION}

As stated above, glutamate, through the activation of ionotropic receptors, plays a central role in the onset of excitotoxicity. Glutamate activates also a class of G-protein coupled receptors, mGlu receptors, that form a family of eight subtypes (mGlu1 to mGlu8) subdivided into three groups on the basis of their amino acid sequence, G-protein coupling, and pharmacological profile. Group I includes mGlu1 and mGlu5 receptors, which are coupled to $\mathrm{G}_{\mathrm{q}} / \mathrm{G}_{11}$ and are functionally linked to polyphosphoinositide hydrolysis and negatively coupled with $\mathrm{K}^{+}$channels (AbdulGhani et al., 1996; Nicoletti et al., 2011). Group II (mGlu2, mGlu3) and group III (mGlu4, mGlu6, mGlu7, mGlu8) subtypes are coupled to $G_{i} / G_{0}$, negatively regulate adenylate cyclase, but can also activate MAP kinase and PI-3-kinase pathways (Iacovelli et al., 2002; Niswender and Conn, 2010; Nicoletti et al., 2011).

mGlu receptors are widely distributed in the CNS, where they are localized at synaptic and extra synaptic levels in neurons and glia. Group I mGlu receptors are generally localized postsynaptically, surrounding ionotropic receptors, and they modulate depolarization and synaptic excitability. Group II and III are mostly expressed at presynaptic level and control the release of neurotransmitters as reviewed in Niswender and Conn (2010), Ribeiro et al. (2017). mGlu receptor subtypes form homo- and heterodimers (Kammermeier, 2012; Yin et al., 2014; Vafabakhsh et al., 2015). In addition, $\mathrm{G}_{\mathrm{i}}$-coupled $\mathrm{mGlu}$ receptors dimerize with other receptors coupled to $\mathrm{G}_{\mathrm{q}}$ such as $5-\mathrm{HT}_{2 A}$, $\beta_{1}$-adrenergic, and $\mathrm{GABA}_{B}$ receptors (Pin and Bettler, 2016). 
Evidence of functional interactions between mGlu receptors and estrogen receptors in neurons also exists (Spampinato et al., 2012b).

Intracellular signaling triggered by mGlu receptors has been mainly studied in neuronal cells, whereas less is known in glial cells (Gerber et al., 2007). Group I mGlu receptors activate MAP kinase playing a key role in protein synthesis-dependent neuronal plasticity (Gerber et al., 2007; Hellyer et al., 2017). Translation and transcription factors targeted by MAPK cascades following mGlu receptors activation have been well characterized (Gerber et al., 2007). Group I mGlu receptors dependent phosphorylation of JNKs increases transcription mediated by activator protein1 (Yang et al., 2006), whereas activation of p38 regulates NF-кB (O’Riordan et al., 2006). More detailed analysis has been carried out in glial cells, and specifically in astrocytes, where stimulation of MAPK and PI3K pathways via mGlu3 receptor increases the production of neurotrophic factors (Bruno et al., 1998; Caraci et al., 2011; Durand et al., 2017) promoting neuroprotection against different toxic insults (Ribeiro et al., 2017). When moving to group III mGlu receptors, mGlu4 receptor activation in cultured rat neural stem cells results in inhibition of JNK and p38 mitogen-activated protein kinase, which downregulates the expression of procaspase-8/9/3 and reverses the $\mathrm{Bcl}-2 / \mathrm{Bax}$ balance, finally preventing $\mathrm{H}_{2} \mathrm{O}_{2}$-mediated cell death (Zhang et al., 2015). A protective role for mGlu7 receptor has also been recently found in glial cells and it involves the activation of PI3K/Akt and MAPK/ERK1/2 pathways (Jantas et al., 2018).

According to the principles of "ligand bias" and "functional selectivity," a G-protein coupled receptor can signal via a canonical pathway mediated by the $\mathrm{G} \alpha$ subunit and via non-canonical pathways (e.g., MAPK activation) mediated by scaffolding proteins such as $\beta$-arrestin (Iacovelli et al., 2014; Hathaway et al., 2015). Recent evidence suggests that mGlu receptors associate with $\beta$-arrestin in the initiation of intracellular cascades affecting cellular responses (Hathaway et al., 2015; Hellyer et al., 2017). The recruitment of $\beta$-arrestin-dependent signaling pathways occurs in response to G-protein coupled Receptor Kinase (GRK)-dependent phosphorylation and it is strictly ligand-dependent (Hellyer et al., 2017). Future studies are needed in astrocytes and microglial cells to assess whether specific ligands with a functional selectivity can exert different effects on intracellular signaling pathways (e.g., MAPK and PI3K) in neuronal and glial cells.

Of note, the expression of mGlu receptors is developmentally regulated. mRNA levels for mGlu1, mGlu2, and mGlu4 receptors are low at birth and increase during postnatal development (Lujan et al., 2005). In addition, the expression of the shorter mGlu5a receptor isoform is higher in prenatal stages, and mainly detected in cortex, hippocampus and subventricular zone, where it colocalizes with neural progenitors (Boer et al., 2010), astrocytes and microglia. In contrast, in mature brain, mGlu5b receptor is the main isoform expressed (Romano et al., 2002; Lujan et al., 2005).

In glial cells, mGlu1, mGlu3, and mGlu5 receptors are found in astrocytes whereas mGlu2, mGlu3, and mGlu5 receptors are expressed in microglial cells. In oligodendrocytes, mGlu1 and mGlu4 are highly expressed (Ribeiro et al., 2017), whereas mGlu5a and $\mathrm{mGlu} 2 / 3$ receptors are present in early developmental stages and downregulated in mature $\mathrm{MBP}+$ oligodendrocytes (Luyt et al., 2003; Deng et al., 2004; Spampinato et al., 2014).

Glial mGlu receptors regulate glial cell proliferation (Ciccarelli et al., 1997), the release of growth factors, cytokines (Ciccarelli et al., 1999; Aronica et al., 2005b), and neurotransmitters including glutamate, ATP and adenosine, which propagate $\mathrm{Ca}^{++}$ signaling between astrocytes and other glial cells (Hamilton et al., 2010). Glial mGlu receptors modulate also the activity and the expression of glutamate transporters, thus participating in the regulation of synaptic function (Aronica et al., 2003b; Vermeiren et al., 2005). Glutamatergic system plays a key role in the pathophysiology of chronic pain and in particular in central sensitization (Guida et al., 2015; Hossain et al., 2017) and neurodegenerative processes leading to cognitive deficits (Giordano et al., 2012). Microglial activation significantly contributes to central sensitization and neurodegeneration promoting the transition from acute to chronic pain (Ji et al., 2014; Hossain et al., 2017). According to this scenario mGlu receptors expressed on glial cells (microglia and astrocytes) might exert a key role in the pathogenesis of chronic pain by modulating both glutamate release and neuroinflammatory phenomena (Chiechio, 2016; Palazzo et al., 2017).

\section{GROUP I mGlu RECEPTORS}

In physiological conditions, the expression of mGlu1 receptor is very low in astrocytes as well as in cultured cortical astrocytes grown in conventional media. In contrast, the expression is higher in reactive astrocytes of ALS spinal cord (Agrawal et al., 1998; Aronica et al., 2001; Anneser et al., 2004).

Expression of mGlu5 in astrocytes is high prenatally, but decreases after birth (Cai et al., 2000; Yang et al., 2012; Iyer et al., 2014). In physiological conditions, the activity of mGlu5 receptor in cortical astrocytes defines the frequency of $\mathrm{Ca}^{++}$ oscillations (Bradley and Challiss, 2011) and the release of gliotransmitters (Agulhon et al., 2008; Fiacco et al., 2009). mGlu5 overexpression has been reported in different neurodegenerative disorders (Ribeiro et al., 2017), in particular in reactive astrocytes surroundings A $\beta$ plaques (Shrivastava et al., 2013), spinal cord lesions (Gwak and Hulsebosch, 2005), MS lesion (Geurts et al., 2003), ALS (Aronica et al., 2001), PD (Tison et al., 2016), and in hippocampal astrocytes from Down syndrome patients (Iyer et al., 2014).

Accordingly, in vitro, mGlu5 receptor expression occurs as a reactive response: both $\mathrm{mRNA}$ and protein levels are induced in astrocytes grown in media enriched with growth factors (FGF, EGF, TGF- $\beta 1$ ) (Miller et al., 1995; Balazs et al., 1997), or exposed to A $\beta$ oligomers (Casley et al., 2009; Lim et al., 2013).

mGlu5 receptor actively regulates glutamate transmission, acting as a sensor of extracellular glutamate concentrations and inducing activation of the glial glutamate transporter GLT-1 (Vermeiren et al., 2005). In contrast, after sustained mGlu5 stimulation, both GLAST and GLT-1 activity are reduced (Aronica et al., 2003a). In astrocytes derived from 
hSOD1-G93A rats, an established model of ALS, increased expression of mGlu5 receptor mRNA is accompanied by reduced GLT-1 activity and enhanced glutamate-induced excitotoxicity (Vermeiren et al., 2006). Similarly, the accumulation of the glial glutamate and the consequent excitotoxicity described in a mouse model of epilepsy have been related to mGlu5 receptor overexpression in hippocampal astrocytes. Accordingly, the mGlu5 receptor antagonist MPEP, attenuates gliotransmission, preventing neuronal death, with no change of synaptic transmission (Ding et al., 2007).

In the AD APPswe/PS1 transgenic mouse model, high expression of mGlu5 receptor has been described in astrocytes surroundings $A \beta$ plaques, associated to $\mathrm{Ca}^{++}$signaling dysregulation and ATP abnormal release (Shrivastava et al., 2013). As previously described for mGlu1 receptor in neurons exposed to an excitotoxic insult (Spampinato et al., 2012a), astrocytic mGlu5 receptor may activate two opposite pathways: on one side, stimulation of phospholipase C, with ensuing increased intracellular $\mathrm{Ca}^{++}$concentrations, may lead to cell death; on the other hand, however, this effect could be counteracted by alternative activation of the ERK1/2 pathway, through a Homer-dependent mechanism (Paquet et al., 2013). Interestingly, in cultured cortical astrocytes, inflammatory cytokines reduce the expression of mGlu5 receptor (Aronica et al., 2005c; Berger et al., 2012), suggesting a protective adaptation to prevent excitotoxicity (Berger et al., 2012). Furthermore, pharmacological blockade of mGlu5 in astroglial cells prevents motor neurons excitotoxicity (D'Antoni et al., 2011). The inhibition of mGlu5 receptor activity on astrocytes may contribute to the reduction of an inflammatory state in the CNS. Treatment with the mGlu5 receptor antagonist MPEP prevented in fact astrocytic secretion of the inflammatory cytokines IL-6 and IL-8 (Shah et al., 2012).

In cultured microglia, the expression of mGlu1 receptor is barely detectable (Byrnes et al., 2009), but it has been reported in vivo in selected microglia cell populations in MS (Klaver et al., 2013). Similarly, the expression of mGlu5 receptor mRNA is low in cultured microglia compared to astrocytes. However, PET imaging studies in animal models exposed to inflammatory stimuli have shown that mGlu5 receptor activation reduced the inflammatory response (Drouin-Ouellet et al., 2011).

In vitro, administration of the non-selective group I agonist DHPG, reduced the number of activated microglia (Farso et al., 2009), while the selective mGlu5 receptor agonist CHPG prevented microglial proliferation induced by LPS (Huang et al., 2018), microglial death induced by OGD (Ye et al., 2017), and the expression of several inflammatory cytokines (Byrnes et al., 2009; Loane et al., 2009; Beneventano et al., 2017). The potential of mGlu5 receptor as a new pharmacological target appears also very interesting in traumatic conditions, such as spinal cord lesions or other traumatic events, where reactive microglia, surroundings the area of the lesion, overexpress mGlu5 receptor. In both TBI models and spinal cord lesions, the delayed CHPG administration, also one month after the traumatic event, reduced the number of reactive microglia and the chronic postinjury inflammation (Byrnes et al., 2012; Wang et al., 2013). In $\mathrm{TBI}$ and spinal cord lesion, BBB damage may further activate microglia, due to the access in the CNS of blood-borne proteins such as fibrinogen, that induces microglial phagocytic phenotype and the release of inflammatory cytokines, leading to neurotoxicity (Piers et al., 2011). The BBB in normal conditions prevents the access of fibrinogen and other proteins and immune cells that are present in the blood, but its damage is a common event in traumatic injuries (TBI, SCI), ischemic events and neurodegenerative disorders (Zhao et al., 2015), such as AD, where increased barrier permeability is observed (Spampinato et al., 2017). In vitro, exposure of microglia to fibrinogen in the presence of the Glu5 receptor PAM (CDPPB) prevented microglia activation and neuronal toxicity (Piers et al., 2011), further underlying the neuroprotective potential of mGlu5 agonists in reducing neuroinflammation.

(RS)-2-chloro-5-hydroxyphenylglycine may prevent microglial activation by releasing BDNF and inducing expression of its receptor Trkb, as observed in BV2 microglia cells (Ye et al., 2017). Recently it has been demonstrated that microglia, as many other cell types, communicate with the neighbor cells through shedding of microvesicles that may represent a cargo for neuromodulators, cytokines, and microRNA (Verderio, 2013). In BV2 microglia cells, CHPG induced an increased release of microvesicles carrying the inflammatory miRNA146a (Beneventano et al., 2017), suggesting a pro-inflammatory role of mGlu5 receptor. It has also been suggested that LPS binds directly to mGlu5 receptor inducing $\mathrm{Ca}^{++}$oscillations and NF$\kappa B$ activity, while attenuating TNF $\alpha$ production (Liu et al., 2014). All these data suggest that microglial mGlu5 receptor exerts an ambivalent role in inflammation.

The neuroprotective potential of mGlu5 receptor agonist CHPG in reducing microglia-induced neuroinflammation may be limited by the fact that the drug has only partial selectivity, poor $\mathrm{BBB}$ penetration, and induces a rapid receptor desensitization (Homayoun and Moghaddam, 2010). mGlu5 receptor PAMs have been investigated as potential therapeutic agents in neurological disorders (Xue et al., 2014). In vitro, exposure of microglia to mGlu5 receptor PAMs has demonstrated a better control in comparison to CHPG in preventing microglia activation after inflammatory insults (Xue et al., 2014). In vivo administration of the mGlu5 receptor PAM, VU0360172, prevented neuronal loss in a TBI model in mice by reducing microglia-induced inflammation (Loane et al., 2014). An open question for future drug discovery processes in neurodegenerative disorders remains how to reconcile the protective effects observed with mGlu5 receptor antagonists on astrocytes, in different experimental models of neurodegeneration, with the anti-inflammatory action of mGlu5 receptor PAMs on microglia, as reported in TBI (Xue et al., 2014). Furthermore we cannot forget that, in neurons, mGlu5 receptors physically interact with NMDA receptors playing a permissive role in mechanisms of excitotoxic neuronal death (Bruno et al., 2017). Accordingly, selective NAMs of mGlu5 receptors are consistently neuroprotective in models of $\mathrm{PD}$ and $\mathrm{AD}$ (Bruno et al., 2017).

As already stated, the expression of group I mGlu receptors in oligodendrocytes is stage dependent. mGlu1 receptor is expressed in the somas of GalC+ oligodendrocytes in prenatal ages and 
during the first two postnatal weeks (P3-P14), while later on mGlu1 receptor is localized exclusively at cell processes. mGlu5 receptor shows a similar distribution, although its expression is lower than mGlu1 and it peaks earlier, at P3-P6. A similar pattern is described in human white matter (Jantzie et al., 2010). Both oligodendrocytes and OPC are very sensitive to glutamate mediated toxicity after hypoxia-ischemia (Deng et al., 2003; Fern et al., 2014) and in MS (Macrez et al., 2016). Activation of mGlu1 receptor by DHPG prevented OPC death induced by kainate (Kelland and Toms, 2001; Deng et al., 2004) and non-excitotoxic agents by maintaining the intracellular levels of glutathione and thus reducing oxidative stress (Deng et al., 2004). mGlu5 receptor activation prevented also staurosporine-induced OPC death (Luyt et al., 2006). Starting from this evidence, selective group I mGlu receptor agonists have been studied in periventricular leukomalacia, a condition characterized by OPC damage, that affects the white matter in premature infants after hypoxiaischemia (Jantzie et al., 2010). Butt et al. (2017) demonstrated that group I receptor agonists can prevent hypoxia-ischemia-induced oligodendrocyte death at all stages of differentiation. Further studies are needed to establish the role of mGlu1 receptor as a new pharmacological target to prevent oligodendrocyte loss in neurodegenerative disorders such as MS, where OPCs are highly vulnerable to excitotoxic damage (Newcombe et al., 2008).

\section{GROUP II mGlu RECEPTORS}

Group II includes mGlu2 and mGlu3 receptors, which are coupled to $G_{i} / G_{0}$ proteins and have been recently studied as a relevant pharmacological target in neurodegenerative disorders (Bruno et al., 2017). Both mGlu2 and mGlu3 receptors are preferentially localized in the pre-terminal region of axon terminals, where they negatively regulate neurotransmitter release. Only mGlu3 receptor is expressed in astrocytes and is present at all developmental stages (Sun et al., 2013), whereas microglial cells express both mGlu2 and mGlu3 receptors (Geurts et al., 2003). mGlu2/3 receptors levels increase in astrocytes in response to FGF and EGF (Aronica et al., 2003a) and after exposure to pro-inflammatory cytokines (TNF $\alpha$ and IL-1 $\beta$ ) (Berger et al., 2012). mGlu3 receptor actively participates in the control of extracellular glutamate by increasing the expression of GLAST and GLT-1 (Gegelashvili et al., 2000; Aronica et al., 2003a; Yao et al., 2005; Zhou et al., 2006). Hence, the use of mGlu3 receptor agonists and/or PAMs has been proposed in the treatment of ALS in which a defect of GLT-1 has been well described (Rothstein et al., 1995; Battaglia et al., 2015). In addition, astrocytic mGlu3 receptors, through activation of MAPK and PI3K pathways, lead to neuroprotection by increasing synthesis and secretion of neurotrophic factors (Bruno et al., 2017), among others, TGF- $\beta 1$, that prevents both NMDA- and $\mathrm{A} \beta$-induced toxicity on neurons (Bruno et al., 1998; Corti et al., 2007; Caraci et al., 2011) and GDNF. The latter is an established neurotrophic agent for nigral dopaminergic neurons, and has shown neuroprotective and restorative activity in a variety of preclinical models of parkinsonism (Ibanez and Andressoo, 2017). It also protects cultured spinal motor neurons from excitotoxicity (Battaglia et al., 2015). Pharmacological activation of mGlu3 receptor in mice increases GDNF mRNA and protein levels in striatal neurons (Battaglia et al., 2009). Hence, selective mGlu3 receptor enhancers may be effective in slowing neuronal degeneration in different conditions such as ALS (Battaglia et al., 2015) and PD (Bruno et al., 2017).

In this regard, a glial-neuronal interaction mediated by astrocytic mGlu3 receptors seems to play a critical role. Early studies have shown that $\mathrm{mGlu} 2 / 3$ receptors agonists protect cortical neurons against excitotoxic death only in the presence of astrocytes (Caraci et al., 2012; Bruno et al., 2017). Studies carried out in cultured astrocytes from mGlu3(-/-) mice (Corti et al., 2007; Caraci et al., 2011; Battaglia et al., 2015) have clearly demonstrated the key role of astrocytic mGlu3 receptor in mediating the neuroprotective effects of $\mathrm{mGlu} 2 / 3$ receptor agonists. Activation of mGlu3 receptor activity also protects astrocytes from OGD (Ciccarelli et al., 2007) and nitric oxide damage, due to the reduction of cAMP content and consequent activation of PI3K/Akt pathway (Durand et al., 2010, 2013).

mGlu3 receptor might represent a relevant pharmacological target to develop disease-modifying drugs in AD (Caraci et al., 2018a). Although no clear data are available in human AD brains, mGlu3 receptor expression appears reduced in several animal models of AD (Dewar et al., 1991; Cha et al., 2001; Durand et al., 2014; Knezevic and Mizrahi, 2018). When treated with the mGlu2/3 receptor agonist LY379268, astrocytes in vitro reduced neuronal $A \beta$ toxicity through the release of neuroprotective factors such as TGF- $\beta 1$ (Caraci et al., 2011) and BDNF (Durand et al., 2017). TGF- $\beta 1$ is known to exert anti-inflammatory and neuroprotective effects in experimental models of $\mathrm{AD}$ (Chen et al., 2015), and stimulates $A \beta$ clearance by microglia (Tichauer and von Bernhardi, 2012). It also exerts a key role in synaptic plasticity and memory formation promoting the transition from early to late LTP (Caraci et al., 2015). A selective deficit of TGF- $\beta 1$ signaling has been found in an early phase of AD and appears to critically contribute to neuroinflammation and cognitive decline in AD (Caraci et al., 2018b). Rescue of TGF$\beta 1$ signaling represents therefore a new pharmacological strategy to yield neuroprotection in $\mathrm{AD}$. Activation of mGlu3 receptor can positively interfere also with other relevant steps of $\mathrm{AD}$ pathogenesis by reducing $A \beta$ production (Durand et al., 2014) or increasing $A \beta$ clearance (Durand et al., 2017). Astroglial mGlu3 receptors stimulate the activity of $\alpha$-secretase, the enzyme that cleaves APP downstream of the N-terminus domain of $\mathrm{A} \beta_{(1-42)}$ (Durand et al., 2014). When exposed to LY379268, astrocytes reduce the levels of $\beta$-secretase, while increasing the expression of $\operatorname{sAPP} \alpha$, thereby reducing neurotoxic $\mathrm{A} \beta$. Recently, it has been demonstrated that LY379268 can increase A $\beta$ uptake in astrocytes and microglia, finally promoting $A \beta$ removal from the extracellular space (Durand et al., 2017). The contribution of mGlu3 receptor seems equivocal because $A \beta$ phagocytosis was not prevented by LY2389575, a selective mGlu3 receptor NAM, suggesting that the effects observed after LY379268 stimulation can also involve mGlu2 receptor activation (Durand et al., 2017).

Microglia respond to $\mathrm{A} \beta$ with increased glutamate release (Barger and Basile, 2001). Exposure of microglial cells to the active fragment $A \beta_{(25-35)}$ induces also mGlu2 receptor 
activation, that can lead to increased neurotoxicity (Taylor et al., 2002, 2005). Activation of mGlu2, but not mGlu3 receptors, promotes in fact a pro-inflammatory and neurotoxic phenotype that releases TNF- $\alpha$ and FAS-L, and enhanced microglial reactivity in response to chromogranin-A, up-regulated in $\mathrm{AD}$ (Taylor et al., 2002, 2005).

An open question remains whether activation of microglial mGlu3 receptor can promote the release of TGF- $\beta 1$, then contributing to the overall neuroprotective activity of LY379268 observed in $A \beta$-treated mixed neuronal cultures (Caraci et al., 2011).

It is well known that microglial activation plays a central role in the pathogenesis of MS (Strachan-Whaley et al., 2014). Exposure to myelin fragments induces microglia activation in vitro, promoting the release of glutamate and TNF- $\alpha$, followed by neuronal death. Interestingly, activation of microglial mGlu2 receptor exacerbates myelin-evoked neurotoxicity, whilst activation of mGlu3 receptor is protective (Pinteaux-Jones et al., 2008).

Suboptimal neuroprotective effects of orthosteric mGlu2/3 receptor agonists have been observed in animal models of global and focal brain ischemia (Bond et al., 1998; Bond et al., 2000), probably due to the involvement of mGlu2 receptors expressed in neurons (Corti et al., 2007; Motolese et al., 2015; Mastroiacovo et al., 2017). However, the role of microglial mGlu2 receptor in stroke ischemia has not been fully elucidated. mGlu2 and mGlu3 receptors are expressed by microglia in the ischemic penumbra, where apoptotic neuronal death develops slowly, making this area more amenable to therapeutic intervention. Microglial cells mediate neurotoxicity in the stroke penumbra (Kaushal and Schlichter, 2008) and in experimental models of ischemia, it has been demonstrated that glutamate, released by "ischemic" neurons, activates microglia through group II mGlu receptors with the following activation of NF- $\mathrm{KB}$, induction of TNF- $\alpha$, and subsequent neuronal death (Kaushal and Schlichter, 2008). New studies should be conducted in cultured microglia from mGlu2(-/-) mice to better understand the role of microglial mGlu2 receptor in the pathophysiology of stroke ischemia.

\section{GROUP III mGlu RECEPTORS}

The function of group III mGlu receptors in astrocytes has not been fully explored. They are almost undetectable in gray matter of normal human brains (Blumcke et al., 1996; Tang and Lee, 2001), although the expression of mGlu4 receptor, and occasionally of mGlu8 receptor, was described in reactive astrocytes surrounding MS lesions (Geurts et al., 2005) as well as in other pathological conditions (Tang and Lee, 2001; Aronica et al., 2003b). The expression of mGlu4 receptor in astrocytes cultured in vitro is still debated. Some studies, but not others (Ciccarelli et al., 1997), reported the expression in primary cortical cultures (?), and induction after exposure to LPS (Spampinato et al., 2014). In contrast, mGlu7 receptor subtype is not expressed in glial cells (Ciccarelli et al., 1997; Aronica et al., 2001; Taylor et al., 2003). Of note, stimulation of mGlu7 and mGlu8 receptors may have a role in the differentiation of progenitor cells in the ventral midbrain (Vernon et al., 2011). Stimulation with the group III mGlu receptor agonist L-AP4 reduces in fact the proliferation of fetal mouse neocortical progenitor, and promotes their differentiation toward an oligodendrocytic and astrocytic phenotype (Nakamichi et al., 2008).

One of the principal effects exerted by mGlu4 receptor agonists is the reduction of the inflammatory response. The expression of the chemoattractant chemokine Rantes (CCL5), whose role in neuroinflammation has been well documented (Sorensen et al., 1999), was significantly downregulated when astrocytes were exposed to inflammatory cytokines in the presence of L-AP4 (?). This in vitro evidence was supported by reduction of the disability score in mice with experimental autoimmune encephalomyelitis treated with 1-AP4 (Besong et al., 2002). In astrocyte and oligodendrocyte co-cultures, L-AP4 prompted astrocytic release of TGF- $\beta 1$, preventing kainateinduced cell death in oligodendrocytes (Spampinato et al., 2014). In contrast, L-AP4 direct treatment on oligodendrocytes was not able to prevent kainate-induced toxicity, but accelerated the differentiation of OPC into mature MBP+ and fully branched oligodendrocytes (Spampinato et al., 2014).

Acting on astrocytes, group III mGlu receptors may also improve glutamate uptake, modulating the expression of both GLT-1 and GLAST. Zhou et al. (2006) reported that L-AP4 prevented neurotoxicity of LPS-treated astrocytes, an effect likely mediated by the increased expression of glutamate transporters. Similar effects were reported in astrocytes exposed to MPTP in the presence of mGlu4 receptor agonists (Yao et al., 2005). In conditions of energy failure, e.g., ischemia, GLT-1 may act paradoxically, running in a reverse mode and thus aggravating the load of glutamate (Rossi et al., 2000; Bonde et al., 2003). Under these conditions, stimulation of mGlu4 receptor may prevent GLT-1 upregulation in reactive astrocytes, thus reducing the aberrant glutamate transport and contributing to neuroprotection (Rodriguez-Kern et al., 2003).

In cultured microglia, the expression of mGlu4, 6 and 8 receptors has been clearly reported (Taylor et al., 2003). In MS patients, mGlu8 receptor was described in the microglial/macrophage line, in particular in the parenchyma and perivascular cuff (Geurts et al., 2003). The overexpression of the receptor in these areas may be induced by the presence of specific cytokines and growth factors released by the environment surrounding the lesions.

As reported (Taylor et al., 2003), agonists acting on group III mGlu receptors prevent microglia activation in vitro. The mechanisms involved in these processes were not clarified, but the release of trophic factors from microglia (Conn and Pin, 1997), or reduced glutamate discharge (Taylor et al., 2003) could be claimed. Glutamate may in fact act in a negative feedback loop reducing its own release in inflammatory states (McMullan et al., 2012). Further, in vitro exposure of microglia to the mGlu4 receptor PAM, ADX88178, reduced the LPS-induced expression of MHCII and iNOS, while reducing the release of TNF $\alpha$ (Ponnazhagan et al., 2016). 

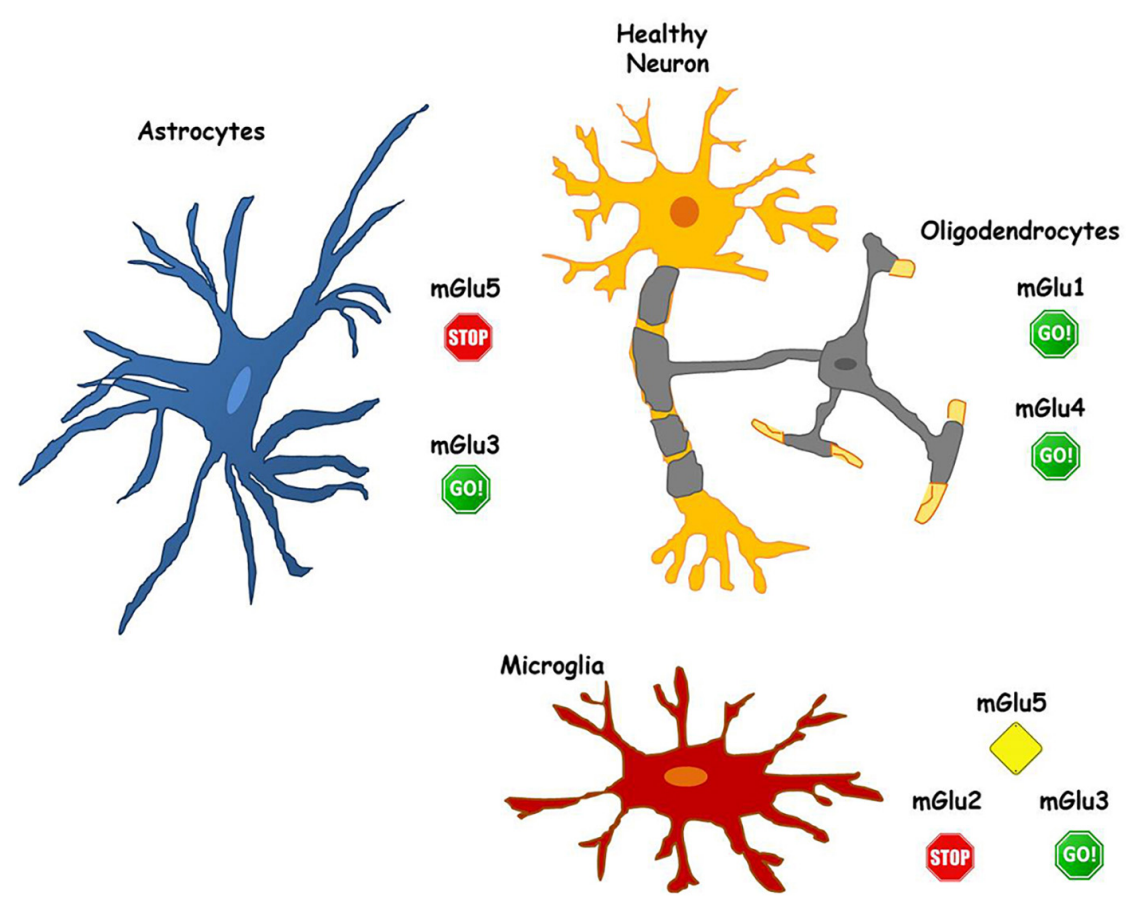

FIGURE 1 | The role of mGlu receptors in different glial cell types. Astrocytes express both mGlu3 and mGlu5 receptors. mGlu3 receptor stimulation initiates mechanisms that induce neuroprotection, while mGlu5 receptor activity promotes neuronal damage. Hence, allowing pharmacological activation of mGlu 3 receptor (GO!) and blocking mGlu5 receptor activity (STOP) in astrocytes could be valuable for the maintenance of neuronal health. Similarly, in microglia, mGlu3 receptor stimulation plays beneficial effects on neurons (GO!), while blockade of mGlu2 (STOP) appears necessary to prevent neurotoxicity. Less defined is the function of glial mGlu5 receptor that, playing a dual role, may be a more complex target for pharmacological intervention (Alert yellow sign). Pharmacological activation of both mGlu1 and mGlu4 receptors, expressed in oligodendrocytes, appear to be neuroprotective (GO! sign).

mGluR4, for its anatomical distribution and function, seems to be an interesting pharmacological target for the treatment of PD. mGluR4 orthosteric agonists have been tested in neurotoxin-based rat models of $\mathrm{PD}$, where they reduced signs of inflammation and the consequent dopamine neuronal loss (Battaglia et al., 2006; Zhou et al., 2006; Betts et al., 2012). These effects were also observed using more potent, selective and orally bioavailable mGlu4 receptor PAMs, such as ADX71743 (Le Poul et al., 2012). The increasing importance of the potential use of mGlu4 receptor agonists in PD relies in their capability to modulate directly neuronal circuits, and as additive effects, to attenuate pro-inflammatory immune mechanisms associated with PD. Accordingly, VU0155041, a mGlu4 receptor PAM, reduces microglia activation in the substantia nigra pars compacta of 6-OHDA-treated rats (Betts et al., 2012).

\section{CONCLUSION}

Metabotropic glutamate receptors are highly and diffusely expressed in glial cells. This, on one side, increases the options for therapeutic interventions, but, on the other side, makes even more difficult the possibility to target selectively single receptors to yield neuroprotection. As mentioned above, different mGlu receptors may give rise to contrasting outcomes when activated in neurons or in glial cells or even in different types of glial cells (see Figure 1).

mGlu5 receptor agonists for instance, might be detrimental for neuroprotection. On neurons, mGlu5 receptor stimulation has been linked to increased synaptotoxicity in AD and PD models (Bruno et al., 2017). A similar potentiation of neurotoxicity is also observed following activation of mGlu5 receptor in astrocytes. Therefore, the anti-inflammatory effects mediated by the activation of mGlu5 receptor on microglia may be vanished by the effects that mGlu5 receptor agonists could exert acting directly on neurons and/or on astrocytes. However, when considering as a whole the different role of mGlu5 receptor in astrocytes and microglia in neurodegenerative disorders, NAMs of mGlu5 receptor should continue to represent a relevant pharmacological tool to develop new neuroprotective strategies in these diseases, with astrocytes as the main target (see Figure 1).

mGlu3 receptor represents a validated pharmacological target to develop disease-modifying drugs in neurodegenerative disorders such as $\mathrm{AD}$, where the development of mGlu3 receptor PAMs might be successful (Figure 1). These drugs acting on receptors expressed in glial cells exert a relevant neuroprotective activity in $\mathrm{AD}$ models through multiple mechanisms such as the release of neurotrophic factors (TGF- $\beta 1$, BDNF) and the reduction of $A \beta$ production (Bruno et al., 2017). More specifically, drugs with mGlu2 NAM/mGlu3 PAM activities might be considered excellent candidates for the treatment of 
$\mathrm{AD}$. The potential disease-modifying activity of pure mGlu2/3 receptors agonists may be vanished by the detrimental effects of mGlu2 receptor in neurons. Drugs endowed with mGlu2 NAM activity may limit this effect and also cater the potential to restrain microglia-induced neuroinflammation that is consistently found in different neurodegenerative disorders such as $\mathrm{AD}$ and $\mathrm{PD}$.

Finally, the effects mediated by mGlu4 receptor expressed either in astrocytes, microglia and oligodendrocytes appear promising for the development of mGlu4 receptor modulators in the treatment of neurodegenerative disorders (Figure 1). In this regard, the possibility to prevent neuroinflammatory phenomena with mGlu4 PAMs seems particularly intriguing since the effect exerted on glial cells may be synergized by the modulatory activity shown by mGlu4 receptor agonists on the peripheral immune system (Fallarino et al., 2010; Fazio et al., 2014, 2018).

Moving from the evidence discussed in the present review, we believe that targeting astrocytes and microglia with mGlu3

\section{REFERENCES}

Abdul-Ghani, M. A., Valiante, T. A., Carlen, P. L., and Pennefather, P. S. (1996). Metabotropic glutamate receptors coupled to IP3 production mediate inhibition of IAHP in rat dentate granule neurons. J. Neurophysiol. 76, 26912700. doi: 10.1152/jn.1996.76.4.2691

Agrawal, S. K., Theriault, E., and Fehlings, M. G. (1998). Role of group I metabotropic glutamate receptors in traumatic spinal cord white matter injury. J. Neurotrauma 15, 929-941. doi: 10.1089/neu.1998.15.929

Agulhon, C., Petravicz, J., McMullen, A. B., Sweger, E. J., Minton, S. K., Taves, S. R., et al. (2008). What is the role of astrocyte calcium in neurophysiology? Neuron 59, 932-946. doi: 10.1016/j.neuron.2008.09.004

Anneser, J. M., Chahli, C., Ince, P. G., Borasio, G. D., and Shaw, P. J. (2004). Glial proliferation and metabotropic glutamate receptor expression in amyotrophic lateral sclerosis. J. Neuropathol. Exp. Neurol. 63, 831-840. doi: 10.1093/jnen/63. 8.831

Aronica, E., Catania, M. V., Geurts, J., Yankaya, B., and Troost, D. (2001). Immunohistochemical localization of group I and II metabotropic glutamate receptors in control and amyotrophic lateral sclerosis human spinal cord: upregulation in reactive astrocytes. Neuroscience 105, 509-520. doi: 10.1016/ S0306-4522(01)00181-6

Aronica, E., Gorter, J. A., Ijlst-Keizers, H., Rozemuller, A. J., Yankaya, B., Leenstra, S., et al. (2003a). Expression and functional role of mGluR3 and mGluR5 in human astrocytes and glioma cells: opposite regulation of glutamate transporter proteins. Eur. J. Neurosci. 17, 2106-2118. doi: 10.1046/j.1460-9568. 2003.02657.x

Aronica, E., Gorter, J. A., Jansen, G. H., van Veelen, C. W., van Rijen, P. C., Ramkema, M., et al. (2003b). Expression and cell distribution of group I and group II metabotropic glutamate receptor subtypes in taylor-type focal cortical dysplasia. Epilepsia 44, 785-795. doi: 10.1046/j.1528-1157.2003.54802.x

Aronica, E., Gorter, J. A., Redeker, S., Ramkema, M., Spliet, W. G., van Rijen, P. C., et al. (2005a). Distribution, characterization and clinical significance of microglia in glioneuronal tumours from patients with chronic intractable epilepsy. Neuropathol. Appl. Neurobiol. 31, 280-291. doi: 10.1111/j.1365-2990. 2004.00636.x

Aronica, E., Gorter, J. A., Rozemuller, A. J., Yankaya, B., and Troost, D. (2005b). Activation of metabotropic glutamate receptor 3 enhances interleukin (IL)1beta-stimulated release of IL-6 in cultured human astrocytes. Neuroscience 130, 927-933. doi: 10.1016/j.neuroscience.2004.10.024

Aronica, E., Gorter, J. A., Rozemuller, A. J., Yankaya, B., and Troost, D. (2005c). Interleukin-1 beta down-regulates the expression of metabotropic glutamate receptor 5 in cultured human astrocytes. J. Neuroimmunol. 160, 188-194. doi: 10.1016/j.jneuroim.2004.11.015
PAM or oligodendrocytes with mGlu4 PAMs might actually represent a novel pharmacological approach for the treatment of neurodegenerative disorders.

\section{AUTHOR CONTRIBUTIONS}

SFS, MAS, and FC wrote the paper. AC and FN contributed to write the paper and revised it critically for important intellectual content.

\section{FUNDING}

This work was supported by PRIN 2015 (PRIN2015SKN9YT) from the Italian Ministry of University and Research and also by the Italian Ministry of Health Research Program 2018 at Oasi Research Institute, IRCCS, Troina, Italy (RC: 2635257).

Bakiri, Y., Karadottir, R., Cossell, L., and Attwell, D. (2011). Morphological and electrical properties of oligodendrocytes in the white matter of the corpus callosum and cerebellum. J. Physiol. 589(Pt 3), 559-573. doi: 10.1113/jphysiol. 2010.201376

Balazs, R., Miller, S., Romano, C., de Vries, A., Chun, Y., and Cotman, C. W. (1997). Metabotropic glutamate receptor mGluR5 in astrocytes: pharmacological properties and agonist regulation. J. Neurochem. 69, 151-163. doi: 10.1046/j. 1471-4159.1997.69010151.x

Barger, S. W., and Basile, A. S. (2001). Activation of microglia by secreted amyloid precursor protein evokes release of glutamate by cystine exchange and attenuates synaptic function. J. Neurochem. 76, 846-854. doi: 10.1046/j.14714159.2001.00075.x

Battaglia, G., Busceti, C. L., Molinaro, G., Biagioni, F., Traficante, A., Nicoletti, F., et al. (2006). Pharmacological activation of mGlu4 metabotropic glutamate receptors reduces nigrostriatal degeneration in mice treated with 1-methyl4-phenyl-1,2,3,6-tetrahydropyridine. J. Neurosci. 26, 7222-7229. doi: 10.1523/ JNEUROSCI.1595-06.2006

Battaglia, G., Molinaro, G., Riozzi, B., Storto, M., Busceti, C. L., Spinsanti, P., et al. (2009). Activation of mGlu3 receptors stimulates the production of GDNF in striatal neurons. PLoS One 4:e6591. doi: 10.1371/journal.pone. 0006591

Battaglia, G., Riozzi, B., Bucci, D., Di Menna, L., Molinaro, G., Pallottino, S., et al. (2015). Activation of mGlu3 metabotropic glutamate receptors enhances GDNF and GLT-1 formation in the spinal cord and rescues motor neurons in the SOD1 mouse model of amyotrophic lateral sclerosis. Neurobiol. Dis. 74, 126-136. doi: 10.1016/j.nbd.2014.11.012

Benatti, C., Blom, J. M., Rigillo, G., Alboni, S., Zizzi, F., Torta, R., et al. (2016). Disease-induced neuroinflammation and depression. CNS Neurol. Disord. Drug Targets 15, 414-433. doi: 10.2174/1871527315666160321104749

Beneventano, M., Spampinato, S. F., Merlo, S., Chisari, M., Platania, P., Ragusa, M., et al. (2017). Shedding of microvesicles from microglia contributes to the effects induced by metabotropic glutamate receptor 5 activation on neuronal death. Front. Pharmacol. 8:812. doi: 10.3389/fphar.2017. 00812

Berger, J. V., Dumont, A. O., Focant, M. C., Vergouts, M., Sternotte, A., Calas, A. G., et al. (2012). Opposite regulation of metabotropic glutamate receptor 3 and metabotropic glutamate receptor 5 by inflammatory stimuli in cultured microglia and astrocytes. Neuroscience 205, 29-38. doi: 10.1016/j.neuroscience. 2011.12.044

Besong, G., Battaglia, G., D’Onofrio, M., Di Marco, R., Ngomba, R. T., Storto, M., et al. (2002). Activation of group III metabotropic glutamate receptors inhibits the production of RANTES in glial cell cultures. J. Neurosci. 22, 5403-5411. doi: 10.1523/JNEUROSCI.22-13-05403.2002 
Betts, M. J., O'Neill, M. J., and Duty, S. (2012). Allosteric modulation of the group III mGlu4 receptor provides functional neuroprotection in the 6hydroxydopamine rat model of Parkinson's disease. Br. J. Pharmacol. 166, 2317-2330. doi: 10.1111/j.1476-5381.2012.01943.x

Block, M. L., and Hong, J. S. (2007). Chronic microglial activation and progressive dopaminergic neurotoxicity. Biochem. Soc. Trans. 35(Pt 5), 1127-1132. doi: 10.1042/BST0351127

Blumcke, I., Behle, K., Malitschek, B., Kuhn, R., Knopfel, T., Wolf, H. K., et al. (1996). Immunohistochemical distribution of metabotropic glutamate receptor subtypes mGluR1b, mGluR2/3, mGluR4a and mGluR5 in human hippocampus. Brain Res. 736, 217-226. doi: 10.1016/0006-8993(96)00697-X

Boer, K., Encha-Razavi, F., Sinico, M., and Aronica, E. (2010). Differential distribution of group I metabotropic glutamate receptors in developing human cortex. Brain Res. 1324, 24-33. doi: 10.1016/j.brainres.2010.02.005

Bond, A., Jones, N. M., Hicks, C. A., Whiffin, G. M., Ward, M. A., O’Neill, M. F., et al. (2000). Neuroprotective effects of LY379268, a selective mGlu2/3 receptor agonist: investigations into possible mechanism of action in vivo. J. Pharmacol. Exp. Ther. 294, 800-809.

Bond, A., O’Neill, M. J., Hicks, C. A., Monn, J. A., and Lodge, D. (1998). Neuroprotective effects of a systemically active group II metabotropic glutamate receptor agonist LY354740 in a gerbil model of global ischaemia. Neuroreport 9 , 1191-1193. doi: 10.1097/00001756-199804200-00042

Bonde, C., Sarup, A., Schousboe, A., Gegelashvili, G., Zimmer, J., and Noraberg, J. (2003). Neurotoxic and neuroprotective effects of the glutamate transporter inhibitor DL-threo-beta-benzyloxyaspartate (DL-TBOA) during physiological and ischemia-like conditions. Neurochem. Int. 43, 371-380. doi: 10.1016/S01970186(03)00024-X

Bradley, S. J., and Challiss, R. A. (2011). Defining protein kinase/phosphatase isoenzymic regulation of $\mathrm{mGlu}(5)$ receptor-stimulated phospholipase $\mathrm{C}$ and $\mathrm{Ca}_{2}{ }^{+}$responses in astrocytes. Br. J. Pharmacol. 164, 755-771. doi: 10.1111/j. 1476-5381.2011.01421.x

Bruno, V., Battaglia, G., Casabona, G., Copani, A., Caciagli, F., and Nicoletti, F. (1998). Neuroprotection by glial metabotropic glutamate receptors is mediated by transforming growth factor-beta. J. Neurosci. 18, 9594-9600. doi: 10.1523/ JNEUROSCI.18-23-09594.1998

Bruno, V., Caraci, F., Copani, A., Matrisciano, F., Nicoletti, F., and Battaglia, G. (2017). The impact of metabotropic glutamate receptors into active neurodegenerative processes: a "dark side" in the development of new symptomatic treatments for neurologic and psychiatric disorders. Neuropharmacology 115, 180-192. doi: 10.1016/j.neuropharm.2016.04.044

Butt, A. M., Vanzulli, I., Papanikolaou, M., De La Rocha, I. C., and Hawkins, V. E. (2017). Metabotropic glutamate receptors protect oligodendrocytes from acute ischemia in the mouse optic nerve. Neurochem. Res. 42, 2468-2478. doi: 10.1007/s11064-017-2220-1

Byrnes, K. R., Loane, D. J., Stoica, B. A., Zhang, J., and Faden, A. I. (2012). Delayed mGluR5 activation limits neuroinflammation and neurodegeneration after traumatic brain injury. J. Neuroinflammation 9:43. doi: 10.1186/17422094-9-43

Byrnes, K. R., Stoica, B., Loane, D. J., Riccio, A., Davis, M. I., and Faden, A. I. (2009). Metabotropic glutamate receptor 5 activation inhibits microglial associated inflammation and neurotoxicity. Glia 57, 550-560. doi: 10.1002/glia.20783

Cai, Z., Schools, G. P., and Kimelberg, H. K. (2000). Metabotropic glutamate receptors in acutely isolated hippocampal astrocytes: developmental changes of mGluR5 mRNA and functional expression. Glia 29, 70-80. doi: 10.1002/(SICI) 1098-1136(20000101)29:1<70::AID-GLIA7>3.0.CO;2-V

Caraci, F., Gulisano, W., Guida, C. A., Impellizzeri, A. A., Drago, F., Puzzo, D., et al. (2015). A key role for TGF-betal in hippocampal synaptic plasticity and memory. Sci. Rep. 5:11252. doi: 10.1038/srep11252

Caraci, F., Molinaro, G., Battaglia, G., Giuffrida, M. L., Riozzi, B., Traficante, A., et al. (2011). Targeting group II metabotropic glutamate (mGlu) receptors for the treatment of psychosis associated with Alzheimer's disease: selective activation of mGlu2 receptors amplifies beta-amyloid toxicity in cultured neurons, whereas dual activation of mGlu2 and mGlu3 receptors is neuroprotective. Mol. Pharmacol. 79, 618-626. doi: 10.1124/mol.110. 067488

Caraci, F., Nicoletti, F., and Copani, A. (2018a). Metabotropic glutamate receptors: the potential for therapeutic applications in Alzheimer's disease. Curr. Opin. Pharmacol. 38, 1-7. doi: 10.1016/j.coph.2017.12.001
Caraci, F., Spampinato, S. F., Morgese, M. G., Tascedda, F., Salluzzo, M. G., Giambirtone, M. C., et al. (2018b). Neurobiological links between depression and $\mathrm{AD}$ : the role of TGF-betal signaling as a new pharmacological target. Pharmacol. Res. 130, 374-384. doi: 10.1016/j.phrs.2018.02.007

Caraci, F., Spampinato, S., Sortino, M. A., Bosco, P., Battaglia, G., Bruno, V., et al. (2012). Dysfunction of TGF-betal signaling in Alzheimer's disease: perspectives for neuroprotection. Cell Tissue Res. 347, 291-301. doi: 10.1007/s00441-0111230-6

Casley, C. S., Lakics, V., Lee, H. G., Broad, L. M., Day, T. A., Cluett, T., et al. (2009). Up-regulation of astrocyte metabotropic glutamate receptor 5 by amyloid-beta peptide. Brain Res. 1260, 65-75. doi: 10.1016/j.brainres.2008.12.082

Cha, J. H., Farrell, L. A., Ahmed, S. F., Frey, A., Hsiao-Ashe, K. K., Young, A. B., et al. (2001). Glutamate receptor dysregulation in the hippocampus of transgenic mice carrying mutated human amyloid precursor protein. Neurobiol. Dis. 8, 90-102. doi: 10.1006/nbdi.2000.0330

Chen, J. H., Ke, K. F., Lu, J. H., Qiu, Y. H., and Peng, Y. P. (2015). Protection of TGF-betal against neuroinflammation and neurodegeneration in Abeta1-42induced Alzheimer's disease model rats. PLoS One 10:e0116549. doi: 10.1371/ journal.pone.0116549

Chiechio, S. (2016). Modulation of chronic pain by metabotropic glutamate receptors. Adv. Pharmacol. 75, 63-89. doi: 10.1016/bs.apha.2015.11.001

Ciccarelli, R., D’Alimonte, I., Ballerini, P., D’Auro, M., Nargi, E., Buccella, S., et al. (2007). Molecular signalling mediating the protective effect of Al adenosine and mGlu3 metabotropic glutamate receptor activation against apoptosis by oxygen/glucose deprivation in cultured astrocytes. Mol. Pharmacol. 71, 13691380. doi: $10.1124 / \mathrm{mol} .106 .031617$

Ciccarelli, R., Di Iorio, P., Bruno, V., Battaglia, G., D’Alimonte, I., D’Onofrio, M., et al. (1999). Activation of A(1) adenosine or mGlu3 metabotropic glutamate receptors enhances the release of nerve growth factor and S-100beta protein from cultured astrocytes. Glia 27, 275-281. doi: 10.1002/(SICI)10981136(199909)27:3<275::AID-GLIA9>3.0.CO;2-0

Ciccarelli, R., Sureda, F. X., Casabona, G., Di Iorio, P., Caruso, A., Spinella, F., et al. (1997). Opposite influence of the metabotropic glutamate receptor subtypes mGlu3 and -5 on astrocyte proliferation in culture. Glia 21, 390-398. doi: 10.1002/(SICI)1098-1136(199712)21:4<390::AID-GLIA6>3.0.CO;2-7

Conn, P. J., and Pin, J. P. (1997). Pharmacology and functions of metabotropic glutamate receptors. Annu. Rev. Pharmacol. Toxicol. 37, 205-237. doi: 10.1146/ annurev.pharmtox.37.1.205

Corti, C., Battaglia, G., Molinaro, G., Riozzi, B., Pittaluga, A., Corsi, M., et al. (2007). The use of knock-out mice unravels distinct roles for mGlu2 and mGlu3 metabotropic glutamate receptors in mechanisms of neurodegeneration/neuroprotection. J. Neurosci. 27, 8297-8308. doi: 10.1523/ JNEUROSCI.1889-07.2007

D’Antoni, S., Berretta, A., Seminara, G., Longone, P., Giuffrida-Stella, A. M., Battaglia, G., et al. (2011). A prolonged pharmacological blockade of type-5 metabotropic glutamate receptors protects cultured spinal cord motor neurons against excitotoxic death. Neurobiol. Dis. 42, 252-264. doi: 10.1016/j.nbd.2011. 01.013

Deng, W., Rosenberg, P. A., Volpe, J. J., and Jensen, F. E. (2003). Calciumpermeable AMPA/kainate receptors mediate toxicity and preconditioning by oxygen-glucose deprivation in oligodendrocyte precursors. Proc. Natl. Acad. Sci. U.S.A. 100, 6801-6806. doi: 10.1073/pnas.1136624100

Deng, W., Wang, H., Rosenberg, P. A., Volpe, J. J., and Jensen, F. E. (2004). Role of metabotropic glutamate receptors in oligodendrocyte excitotoxicity and oxidative stress. Proc. Natl. Acad. Sci. U.S.A. 101, 7751-7756. doi: 10.1073/pnas. 0307850101

Dewapriya, P., Li, Y. X., Himaya, S. W., Pangestuti, R., and Kim, S. K. (2013). Neoechinulin A suppresses amyloid-beta oligomer-induced microglia activation and thereby protects PC-12 cells from inflammation-mediated toxicity. Neurotoxicology 35, 30-40. doi: 10.1016/j.neuro.2012.12.004

Dewar, D., Chalmers, D. T., Graham, D. I., and McCulloch, J. (1991). Glutamate metabotropic and AMPA binding sites are reduced in Alzheimer's disease: an autoradiographic study of the hippocampus. Brain Res. 553, 58-64. doi: 10.1016/0006-8993(91)90230-S

Ding, S., Fellin, T., Zhu, Y., Lee, S. Y., Auberson, Y. P., Meaney, D. F., et al. (2007). Enhanced astrocytic $\mathrm{Ca}_{2}{ }^{+}$signals contribute to neuronal excitotoxicity after status epilepticus. J. Neurosci. 27, 10674-10684. doi: 10.1523/JNEUROSCI. 2001-07.2007 
Doble, A. (1999). The role of excitotoxicity in neurodegenerative disease: implications for therapy. Pharmacol. Ther. 81, 163-221. doi: 10.1016/S01637258(98)00042-4

Drouin-Ouellet, J., Brownell, A. L., Saint-Pierre, M., Fasano, C., Emond, V., Trudeau, L. E., et al. (2011). Neuroinflammation is associated with changes in glial mGluR5 expression and the development of neonatal excitotoxic lesions. Glia 59, 188-199. doi: 10.1002/glia.21086

Dugan, L. L., and Choi, D. W. (1994). Excitotoxicity, free radicals, and cell membrane changes. Ann. Neurol. 35(Suppl.), S17-S21. doi: 10.1002/ana. 410350707

Durand, D., Carniglia, L., Beauquis, J., Caruso, C., Saravia, F., and Lasaga, M. (2014). Astroglial mGlu3 receptors promote alpha-secretase-mediated amyloid precursor protein cleavage. Neuropharmacology 79, 180-189. doi: 10.1016/j. neuropharm.2013.11.015

Durand, D., Carniglia, L., Caruso, C., and Lasaga, M. (2013). mGlu3 receptor and astrocytes: partners in neuroprotection. Neuropharmacology 66, 1-11. doi: 10.1016/j.neuropharm.2012.04.009

Durand, D., Carniglia, L., Turati, J., Ramirez, D., Saba, J., Caruso, C., et al. (2017). Amyloid-beta neurotoxicity and clearance are both regulated by glial group II metabotropic glutamate receptors. Neuropharmacology 123, 274-286. doi: 10.1016/j.neuropharm.2017.05.008

Durand, D., Caruso, C., Carniglia, L., and Lasaga, M. (2010). Metabotropic glutamate receptor 3 activation prevents nitric oxide-induced death in cultured rat astrocytes. J. Neurochem. 112, 420-433. doi: 10.1111/j.1471-4159.2009. 06469.x

Ettle, B., Schlachetzki, J. C. M., and Winkler, J. (2016). Oligodendroglia and myelin in neurodegenerative diseases: more than just bystanders? Mol. Neurobiol. 53, 3046-3062. doi: 10.1007/s12035-015-9205-3

Fallarino, F., Volpi, C., Fazio, F., Notartomaso, S., Vacca, C., Busceti, C., et al. (2010). Metabotropic glutamate receptor-4 modulates adaptive immunity and restrains neuroinflammation. Nat. Med. 16, 897-902. doi: 10.1038/nm.2183

Farso, M. C., O'Shea, R. D., and Beart, P. M. (2009). Evidence group I mGluR drugs modulate the activation profile of lipopolysaccharide-exposed microglia in culture. Neurochem. Res. 34, 1721-1728. doi: 10.1007/s11064-009-9999-3

Fazio, F., Ulivieri, M., Volpi, C., Gargaro, M., and Fallarino, F. (2018). Targeting metabotropic glutamate receptors for the treatment of neuroinflammation. Curr. Opin. Pharmacol. 38, 16-23. doi: 10.1016/j.coph.2018.01.010

Fazio, F., Zappulla, C., Notartomaso, S., Busceti, C., Bessede, A., Scarselli, P., et al. (2014). Cinnabarinic acid, an endogenous agonist of type-4 metabotropic glutamate receptor, suppresses experimental autoimmune encephalomyelitis in mice. Neuropharmacology 81, 237-243. doi: 10.1016/j.neuropharm.2014.02.011

Fellner, L., and Stefanova, N. (2013). The role of glia in alpha-synucleinopathies. Mol. Neurobiol. 47, 575-586. doi: 10.1007/s12035-012-8340-3

Fern, R. F., Matute, C., and Stys, P. K. (2014). White matter injury: ischemic and nonischemic. Glia 62, 1780-1789. doi: 10.1002/glia.22722

Ferrer, I. (2018). Oligodendrogliopathy in neurodegenerative diseases with abnormal protein aggregates: the forgotten partner. Prog. Neurobiol. 169, 24-54. doi: 10.1016/j.pneurobio.2018.07.004

Fiacco, T. A., Agulhon, C., and McCarthy, K. D. (2009). Sorting out astrocyte physiology from pharmacology. Annu. Rev. Pharmacol. Toxicol. 49, 151-174. doi: 10.1146/annurev.pharmtox.011008.145602

Gegelashvili, G., Dehnes, Y., Danbolt, N. C., and Schousboe, A. (2000). The highaffinity glutamate transporters GLT1, GLAST, and EAAT4 are regulated via different signalling mechanisms. Neurochem. Int. 37, 163-170. doi: 10.1016/ S0197-0186(00)00019-X

Gerber, U., Gee, C. E., and Benquet, P. (2007). Metabotropic glutamate receptors: intracellular signaling pathways. Curr. Opin. Pharmacol. 7, 56-61. doi: 10.1016/ j.coph.2006.08.008

Geurts, J. J., Wolswijk, G., Bo, L., Redeker, S., Ramkema, M., Troost, D., et al. (2005). Expression patterns of Group III metabotropic glutamate receptors mGluR4 and mGluR8 in multiple sclerosis lesions. J. Neuroimmunol. 158, 182-190. doi: 10.1016/j.jneuroim.2004.08.012

Geurts, J. J., Wolswijk, G., Bo, L., van der Valk, P., Polman, C. H., Troost, D., et al. (2003). Altered expression patterns of group I and II metabotropic glutamate receptors in multiple sclerosis. Brain 126(Pt 8), 1755-1766. doi: 10.1093/brain/ $\operatorname{awg} 179$

Giordano, C., Cristino, L., Luongo, L., Siniscalco, D., Petrosino, S., Piscitelli, F., et al. (2012). TRPV1-dependent and -independent alterations in the limbic cortex of neuropathic mice: impact on glial caspases and pain perception. Cereb. Cortex 22, 2495-2518. doi: 10.1093/cercor/bhr328

Gomez-Nicola, D., and Perry, V. H. (2015). Microglial dynamics and role in the healthy and diseased brain: a paradigm of functional plasticity. Neuroscientist 21, 169-184. doi: 10.1177/1073858414530512

Guida, F., Luongo, L., Marmo, F., Romano, R., Iannotta, M., Napolitano, F., et al. (2015). Palmitoylethanolamide reduces pain-related behaviors and restores glutamatergic synapses homeostasis in the medial prefrontal cortex of neuropathic mice. Mol. Brain 8:47. doi: 10.1186/s13041-015-0139-5

Gwak, Y. S., and Hulsebosch, C. E. (2005). Upregulation of Group I metabotropic glutamate receptors in neurons and astrocytes in the dorsal horn following spinal cord injury. Exp. Neurol. 195, 236-243. doi: 10.1016/j.expneurol.2005. 05.012

Hamilton, N., Vayro, S., Wigley, R., and Butt, A. M. (2010). Axons and astrocytes release ATP and glutamate to evoke calcium signals in NG2-glia. Glia 58, 66-79. doi: $10.1002 /$ glia.20902

Hardingham, G. E., and Bading, H. (2003). The Yin and Yang of NMDA receptor signalling. Trends Neurosci. 26, 81-89. doi: 10.1016/S0166-2236(02)00040-1

Harris, J. J., and Attwell, D. (2012). The energetics of CNS white matter. J. Neurosci. 32, 356-371. doi: 10.1523/JNEUROSCI.3430-11.2012

Hathaway, H. A., Pshenichkin, S., Grajkowska, E., Gelb, T., Emery, A. C., Wolfe, B. B., et al. (2015). Pharmacological characterization of mGlul receptors in cerebellar granule cells reveals biased agonism. Neuropharmacology 93, 199-208. doi: 10.1016/j.neuropharm.2015.02.007

Hellyer, S., Leach, K., and Gregory, K. J. (2017). Neurobiological insights and novel therapeutic opportunities for CNS disorders from mGlu receptor allosteric and biased modulation. Curr. Opin. Pharmacol. 32, 49-55. doi: 10.1016/j.coph.2016. 10.007

Heneka, M. T., Rodriguez, J. J., and Verkhratsky, A. (2010). Neuroglia in neurodegeneration. Brain Res. Rev. 63, 189-211. doi: 10.1016/j.brainresrev. 2009.11.004

Homayoun, H., and Moghaddam, B. (2010). Group 5 metabotropic glutamate receptors: role in modulating cortical activity and relevance to cognition. Eur. J. Pharmacol. 639, 33-39. doi: 10.1016/j.ejphar.2009.12.042

Hossain, M. Z., Unno, S., Ando, H., Masuda, Y., and Kitagawa, J. (2017). Neuron-glia crosstalk and neuropathic pain: involvement in the modulation of motor activity in the orofacial region. Int. J. Mol. Sci. 18:E2051. doi: 10.3390/ ijms18102051

Huang, Y. Y., Zhang, Q., Zhang, J. N., Zhang, Y. N., Gu, L., Yang, H. M., et al. (2018). Triptolide up-regulates metabotropic glutamate receptor 5 to inhibit microglia activation in the lipopolysaccharide-induced model of Parkinson's disease. Brain Behav. Immun. 71, 93-107. doi: 10.1016/j.bbi.2018. 04.006

Iacovelli, L., Bruno, V., Salvatore, L., Melchiorri, D., Gradini, R., Caricasole, A., et al. (2002). Native group-III metabotropic glutamate receptors are coupled to the mitogen-activated protein kinase/phosphatidylinositol-3-kinase pathways. J. Neurochem. 82, 216-223. doi: 10.1046/j.1471-4159.2002.00929.x

Iacovelli, L., Felicioni, M., Nistico, R., Nicoletti, F., and De Blasi, A. (2014). Selective regulation of recombinantly expressed mGlu7 metabotropic glutamate receptors by $\mathrm{G}$ protein-coupled receptor kinases and arrestins. Neuropharmacology 77, 303-312. doi: 10.1016/j.neuropharm.2013.10.013

Ibanez, C. F., and Andressoo, J. O. (2017). Biology of GDNF and its receptors Relevance for disorders of the central nervous system. Neurobiol. Dis. 97(Pt B), 80-89. doi: 10.1016/j.nbd.2016.01.021

Iyer, A. M., van Scheppingen, J., Milenkovic, I., Anink, J. J., Lim, D., Genazzani, A. A., et al. (2014). Metabotropic glutamate receptor 5 in Down's syndrome hippocampus during development: increased expression in astrocytes. Curr. Alzheimer Res. 11, 694-705.doi: 10.2174/156720501166 6140812115423

Jantas, D., Lech, T., Golda, S., Pilc, A., and Lason, W. (2018). New evidences for a role of mGluR7 in astrocyte survival: possible implications for neuroprotection. Neuropharmacology 141, 223-237. doi: 10.1016/j.neuropharm.2018. 08.035

Jantzie, L. L., Talos, D. M., Selip, D. B., An, L., Jackson, M. C., Folkerth, R. D., et al. (2010). Developmental regulation of group I metabotropic glutamate receptors in the premature brain and their protective role in a rodent model of periventricular leukomalacia. Neuron Glia Biol. 6, 277-288. doi: 10.1017/ S1740925X11000111 
Ji, R. R., Xu, Z. Z., and Gao, Y. J. (2014). Emerging targets in neuroinflammationdriven chronic pain. Nat. Rev. Drug Discov. 13, 533-548. doi: 10.1038/nrd4334

Kammermeier, P. J. (2012). Functional and pharmacological characteristics of metabotropic glutamate receptors $2 / 4$ heterodimers. Mol. Pharmacol. 82, 438447. doi: $10.1124 / \mathrm{mol} .112 .078501$

Kaushal, V., and Schlichter, L. C. (2008). Mechanisms of microglia-mediated neurotoxicity in a new model of the stroke penumbra. J. Neurosci. 28, 22212230. doi: 10.1523/JNEUROSCI.5643-07.2008

Kelland, E. E., and Toms, N. J. (2001). Group I metabotropic glutamate receptors limit AMPA receptor-mediated oligodendrocyte progenitor cell death. Eur. J. Pharmacol. 424, R3-R4. doi: 10.1016/S0014-2999(01)01157-8

Kim, S. U., and de Vellis, J. (2005). Microglia in health and disease. J. Neurosci. Res. 81, 302-313. doi: 10.1002/jnr.20562

Klaver, R., De Vries, H. E., Schenk, G. J., and Geurts, J. J. (2013). Grey matter damage in multiple sclerosis: a pathology perspective. Prion 7, 66-75. doi: $10.4161 /$ pri.23499

Knezevic, D., and Mizrahi, R. (2018). Molecular imaging of neuroinflammation in Alzheimer's disease and mild cognitive impairment. Prog. Neuropsychopharmacol. Biol. Psychiatry 80(Pt B), 123-131. doi: 10.1016/j.pnpbp.2017.05.007

Kobayashi, K., Hayashi, M., Nakano, H., Fukutani, Y., Sasaki, K., Shimazaki, M., et al. (2002). Apoptosis of astrocytes with enhanced lysosomal activity and oligodendrocytes in white matter lesions in Alzheimer's disease. Neuropathol. Appl. Neurobiol. 28, 238-251. doi: 10.1046/j.1365-2990.2002.00390.x

Le Poul, E., Bolea, C., Girard, F., Poli, S., Charvin, D., Campo, B., et al. (2012). A potent and selective metabotropic glutamate receptor 4 positive allosteric modulator improves movement in rodent models of Parkinson's disease. J. Pharmacol. Exp. Ther. 343, 167-177. doi: 10.1124/jpet.112.196063

Lim, D., Iyer, A., Ronco, V., Grolla, A. A., Canonico, P. L., Aronica, E., et al. (2013). Amyloid beta deregulates astroglial mGluR5-mediated calcium signaling via calcineurin and Nf-kB. Glia 61, 1134-1145. doi: 10.1002/glia.22502

Liu, F., Zhou, R., Yan, H., Yin, H., Wu, X., Tan, Y., et al. (2014). Metabotropic glutamate receptor 5 modulates calcium oscillation and innate immune response induced by lipopolysaccharide in microglial cell. Neuroscience 281, 24-34. doi: 10.1016/j.neuroscience.2014.09.034

Liu, G. J., Nagarajah, R., Banati, R. B., and Bennett, M. R. (2009). Glutamate induces directed chemotaxis of microglia. Eur. J. Neurosci. 29, 1108-1118. doi: 10.1111/j.1460-9568.2009.06659.x

Loane, D. J., Stoica, B. A., Pajoohesh-Ganji, A., Byrnes, K. R., and Faden, A. I. (2009). Activation of metabotropic glutamate receptor 5 modulates microglial reactivity and neurotoxicity by inhibiting NADPH oxidase. J. Biol. Chem. 284, 15629-15639. doi: 10.1074/jbc.M806139200

Loane, D. J., Stoica, B. A., Tchantchou, F., Kumar, A., Barrett, J. P., Akintola, T., et al. (2014). Novel mGluR5 positive allosteric modulator improves functional recovery, attenuates neurodegeneration, and alters microglial polarization after experimental traumatic brain injury. Neurotherapeutics 11, 857-869. doi: 10. 1007/s13311-014-0298-6

Lujan, R., Shigemoto, R., and Lopez-Bendito, G. (2005). Glutamate and GABA receptor signalling in the developing brain. Neuroscience 130, 567-580. doi: 10.1016/j.neuroscience.2004.09.042

Luyt, K., Varadi, A., Durant, C. F., and Molnar, E. (2006). Oligodendroglial metabotropic glutamate receptors are developmentally regulated and involved in the prevention of apoptosis. J. Neurochem. 99, 641-656. doi: 10.1111/j.14714159.2006.04103.x

Luyt, K., Varadi, A., and Molnar, E. (2003). Functional metabotropic glutamate receptors are expressed in oligodendrocyte progenitor cells. J. Neurochem. 84, 1452-1464. doi: 10.1046/j.1471-4159.2003.01661.x

Macrez, R., Stys, P. K., Vivien, D., Lipton, S. A., and Docagne, F. (2016). Mechanisms of glutamate toxicity in multiple sclerosis: biomarker and therapeutic opportunities. Lancet Neurol. 15, 1089-1102. doi: 10.1016/S14744422(16)30165-X

Martin, G. M. (2000). Molecular mechanisms of late life dementias. Exp. Gerontol. 35, 439-443. doi: 10.1016/S0531-5565(99)00090-X

Mastroiacovo, F., Moyanova, S., Cannella, M., Gaglione, A., Verhaeghe, R., Bozza, G., et al. (2017). Genetic deletion of mGlu2 metabotropic glutamate receptors improves the short-term outcome of cerebral transient focal ischemia. Mol. Brain 10:39. doi: 10.1186/s13041-017-0319-6
McMullan, S. M., Phanavanh, B., Li, G. G., and Barger, S. W. (2012). Metabotropic glutamate receptors inhibit microglial glutamate release. ASN Neuro 4:e00094. doi: 10.1042/AN20120044

Miller, S., Romano, C., and Cotman, C. W. (1995). Growth factor upregulation of a phosphoinositide-coupled metabotropic glutamate receptor in cortical astrocytes. J. Neurosci. 15, 6103-6109. doi: 10.1523/JNEUROSCI.15-09-06103. 1995

Mosher, K. I., and Wyss-Coray, T. (2014). Microglial dysfunction in brain aging and Alzheimer's disease. Biochem. Pharmacol. 88, 594-604. doi: 10.1016/j.bcp. 2014.01.008

Motolese, M., Mastroiacovo, F., Cannella, M., Bucci, D., Gaglione, A., Riozzi, B., et al. (2015). Targeting type-2 metabotropic glutamate receptors to protect vulnerable hippocampal neurons against ischemic damage. Mol. Brain 8:66. doi: 10.1186/s13041-015-0158-2

Nakamichi, N., Yoshida, K., Ishioka, Y., Makanga, J. O., Fukui, M., Yoneyama, M., et al. (2008). Group III metabotropic glutamate receptor activation suppresses self-replication of undifferentiated neocortical progenitor cells. J. Neurochem. 105, 1996-2012. doi: 10.1111/j.1471-4159.2008.05289.x

Newcombe, J., Uddin, A., Dove, R., Patel, B., Turski, L., Nishizawa, Y., et al. (2008). Glutamate receptor expression in multiple sclerosis lesions. Brain Pathol. 18, 52-61. doi: 10.1111/j.1750-3639.2007.00101.x

Nguyen, D., Alavi, M. V., Kim, K. Y., Kang, T., Scott, R. T., Noh, Y. H., et al. (2011). A new vicious cycle involving glutamate excitotoxicity, oxidative stress and mitochondrial dynamics. Cell Death Dis. 2:e240. doi: 10.1038/cddis.20 11.117

Nicoletti, F., Bockaert, J., Collingridge, G. L., Conn, P. J., Ferraguti, F., Schoepp, D. D., et al. (2011). Metabotropic glutamate receptors: from the workbench to the bedside. Neuropharmacology 60, 1017-1041. doi: 10.1016/j.neuropharm. 2010.10.022

Niswender, C. M., and Conn, P. J. (2010). Metabotropic glutamate receptors: physiology, pharmacology, and disease. Annu. Rev. Pharmacol. Toxicol. 50, 295-322. doi: 10.1146/annurev.pharmtox.011008.145533

Oliet, S. H., Piet, R., and Poulain, D. A. (2001). Control of glutamate clearance and synaptic efficacy by glial coverage of neurons. Science 292, 923-926. doi: $10.1126 /$ science. 1059162

Olmos, G., and Llado, J. (2014). Tumor necrosis factor alpha: a link between neuroinflammation and excitotoxicity. Mediators Inflamm. 2014:861231. doi: $10.1155 / 2014 / 861231$

O’Riordan, K. J., Huang, I. C., Pizzi, M., Spano, P., Boroni, F., Egli, R., et al. (2006). Regulation of nuclear factor kappaB in the hippocampus by group I metabotropic glutamate receptors. J. Neurosci. 26, 4870-4879. doi: 10.1523/ JNEUROSCI.4527-05.2006

Palazzo, E., Marabese, I., Luongo, L., Guida, F., de Novellis, V., and Maione, S. (2017). Nociception modulation by supraspinal group III metabotropic glutamate receptors. J. Neurochem. 141, 507-519. doi: 10.1111/jnc.13725

Paquet, M., Ribeiro, F. M., Guadagno, J., Esseltine, J. L., Ferguson, S. S., and Cregan, S. P. (2013). Role of metabotropic glutamate receptor 5 signaling and homer in oxygen glucose deprivation-mediated astrocyte apoptosis. Mol. Brain 6:9. doi: 10.1186/1756-6606-6-9

Pickering, M., Cumiskey, D., and O'Connor, J. J. (2005). Actions of TNF-alpha on glutamatergic synaptic transmission in the central nervous system. Exp. Physiol. 90, 663-670. doi: 10.1113/expphysiol.2005.030734

Piers, T. M., Heales, S. J., and Pocock, J. M. (2011). Positive allosteric modulation of metabotropic glutamate receptor 5 down-regulates fibrinogen-activated microglia providing neuronal protection. Neurosci. Lett. 505, 140-145. doi: 10.1016/j.neulet.2011.10.007

Pin, J. P., and Bettler, B. (2016). Organization and functions of mGlu and GABAB receptor complexes. Nature 540, 60-68. doi: 10.1038/nature20566

Pinteaux-Jones, F., Sevastou, I. G., Fry, V. A., Heales, S., Baker, D., and Pocock, J. M. (2008). Myelin-induced microglial neurotoxicity can be controlled by microglial metabotropic glutamate receptors. J. Neurochem. 106, 442-454. doi: 10.1111/j.1471-4159.2008.05426.x

Ponnazhagan, R., Harms, A. S., Thome, A. D., Jurkuvenaite, A., Gogliotti, R., Niswender, C. M., et al. (2016). The metabotropic glutamate receptor 4 positive allosteric modulator ADX88178 inhibits inflammatory responses in primary microglia. J. Neuroimmune Pharmacol. 11, 231-237. doi: 10.1007/s11481-0169655-z 
Ribeiro, F. M., Vieira, L. B., Pires, R. G., Olmo, R. P., and Ferguson, S. S. (2017). Metabotropic glutamate receptors and neurodegenerative diseases. Pharmacol. Res. 115, 179-191. doi: 10.1016/j.phrs.2016.11.013

Rodriguez-Kern, A., Gegelashvili, M., Schousboe, A., Zhang, J., Sung, L., and Gegelashvili, G. (2003). Beta-amyloid and brain-derived neurotrophic factor, BDNF, up-regulate the expression of glutamate transporter GLT-1/EAAT2 via different signaling pathways utilizing transcription factor NF-кB. Neurochem. Int. 43, 363-370. doi: 10.1016/s0197-0186(03) 00023-8

Romano, C., Smout, S., Miller, J. K., and O’Malley, K. L. (2002). Developmental regulation of metabotropic glutamate receptor $5 \mathrm{~b}$ protein in rodent brain. Neuroscience 111, 693-698. doi: 10.1016/S0306-4522(02)00042-8

Rosenbluth, J. (2009). Multiple functions of the paranodal junction of myelinated nerve fibers. J. Neurosci. Res. 87, 3250-3258. doi: 10.1002/jnr.22013

Rossi, D. J., Oshima, T., and Attwell, D. (2000). Glutamate release in severe brain ischaemia is mainly by reversed uptake. Nature 403, 316-321. doi: 10.1038/ 35002090

Rothstein, J. D., Van Kammen, M., Levey, A. I., Martin, L. J., and Kuncl, R. W. (1995). Selective loss of glial glutamate transporter GLT-1 in amyotrophic lateral sclerosis. Ann. Neurol. 38, 73-84. doi: 10.1002/ana.410380114

Schafer, D. P., Lehrman, E. K., Kautzman, A. G., Koyama, R., Mardinly, A. R., Yamasaki, R., et al. (2012). Microglia sculpt postnatal neural circuits in an activity and complement-dependent manner. Neuron 74, 691-705. doi: 10. 1016/j.neuron.2012.03.026

Shah, A., Silverstein, P. S., Singh, D. P., and Kumar, A. (2012). Involvement of metabotropic glutamate receptor 5 , AKT/PI3K signaling and NF-kappaB pathway in methamphetamine-mediated increase in IL-6 and IL-8 expression in astrocytes. J. Neuroinflammation 9:52. doi: 10.1186/1742-2094-9-52

Shrivastava, A. N., Kowalewski, J. M., Renner, M., Bousset, L., Koulakoff, A., Melki, R., et al. (2013). beta-amyloid and ATP-induced diffusional trapping of astrocyte and neuronal metabotropic glutamate type-5 receptors. Glia 61, 1673-1686. doi: 10.1002/glia.22548

Sorensen, T. L., Tani, M., Jensen, J., Pierce, V., Lucchinetti, C., Folcik, V. A., et al. (1999). Expression of specific chemokines and chemokine receptors in the central nervous system of multiple sclerosis patients. J. Clin. Invest. 103, 807-815. doi: 10.1172/JCI5150

Spampinato, S. F., Merlo, S., Chisari, M., Nicoletti, F., and Sortino, M. A. (2014). Glial metabotropic glutamate receptor-4 increases maturation and survival of oligodendrocytes. Front. Cell. Neurosci. 8:462. doi: 10.3389/fncel.2014.00462

Spampinato, S. F., Merlo, S., Molinaro, G., Battaglia, G., Bruno, V., Nicoletti, F., et al. (2012a). Dual effect of 17beta-estradiol on NMDA-induced neuronal death: involvement of metabotropic glutamate receptor 1. Endocrinology 153, 5940-5948. doi: 10.1210/en.2012-1799

Spampinato, S. F., Molinaro, G., Merlo, S., Iacovelli, L., Caraci, F., Battaglia, G., et al. (2012b). Estrogen receptors and type 1 metabotropic glutamate receptors are interdependent in protecting cortical neurons against beta-amyloid toxicity. Mol. Pharmacol. 81, 12-20. doi: 10.1124/mol.111.074021

Spampinato, S. F., Merlo, S., Sano, Y., Kanda, T., and Sortino, M. A. (2017). Astrocytes contribute to Abeta-induced blood brain barrier damage through activation of endothelial MMP9. J. Neurochem. 142, 464-477. doi: 10.1111/jnc. 14068

Stevens, B., Allen, N. J., Vazquez, L. E., Howell, G. R., Christopherson, K. S., Nouri, N., et al. (2007). The classical complement cascade mediates CNS synapse elimination. Cell 131, 1164-1178. doi: 10.1016/j.cell.2007.10.036

Strachan-Whaley, M., Rivest, S., and Yong, V. W. (2014). Interactions between microglia and $\mathrm{T}$ cells in multiple sclerosis pathobiology. J. Interferon Cytokine Res. 34, 615-622. doi: 10.1089/jir.2014.0019

Streit, W. J., and Xue, Q. S. (2014). Human CNS immune senescence and neurodegeneration. Curr. Opin. Immunol. 29, 93-96. doi: 10.1016/j.coi.2014.05. 005

Sun, W., McConnell, E., Pare, J. F., Xu, Q., Chen, M., Peng, W., et al. (2013). Glutamate-dependent neuroglial calcium signaling differs between young and adult brain. Science 339, 197-200. doi: 10.1126/science.1226740

Tang, F. R., and Lee, W. L. (2001). Expression of the group II and III metabotropic glutamate receptors in the hippocampus of patients with mesial temporal lobe epilepsy. J. Neurocytol. 30, 137-143. doi: 10.1023/A:1011939223872

Taylor, D. L., Diemel, L. T., Cuzner, M. L., and Pocock, J. M. (2002). Activation of group II metabotropic glutamate receptors underlies microglial reactivity and neurotoxicity following stimulation with chromogranin A, a peptide upregulated in Alzheimer's disease. J. Neurochem. 82, 1179-1191. doi: 10.1046/j. 1471-4159.2002.01062.x

Taylor, D. L., Diemel, L. T., and Pocock, J. M. (2003). Activation of microglial group III metabotropic glutamate receptors protects neurons against microglial neurotoxicity. J. Neurosci. 23, 2150-2160. doi: 10.1523/JNEUROSCI.23-0602150.2003

Taylor, D. L., Jones, F., Kubota, E. S., and Pocock, J. M. (2005). Stimulation of microglial metabotropic glutamate receptor mGlu2 triggers tumor necrosis factor alpha-induced neurotoxicity in concert with microglial-derived Fas ligand. J. Neurosci. 25, 2952-2964. doi: 10.1523/JNEUROSCI.4456-04.2005

Tichauer, J. E., and von Bernhardi, R. (2012). Transforming growth factorbeta stimulates beta amyloid uptake by microglia through Smad3-dependent mechanisms. J. Neurosci. Res. 90, 1970-1980. doi: 10.1002/jnr.23082

Tilleux, S., Berger, J., and Hermans, E. (2007). Induction of astrogliosis by activated microglia is associated with a down-regulation of metabotropic glutamate receptor 5. J. Neuroimmunol. 189, 23-30. doi: 10.1016/j.jneuroim.2007.06.011

Tison, F., Keywood, C., Wakefield, M., Durif, F., Corvol, J. C., Eggert, K., et al. (2016). A phase $2 \mathrm{~A}$ trial of the novel mGluR5-negative allosteric modulator dipraglurant for levodopa-induced dyskinesia in parkinson's disease. Mov. Disord. 31, 1373-1380. doi: 10.1002/mds.26659

Tomimoto, H., Akiguchi, I., Wakita, H., and Kimura, J. (1997). [White matter lesions after occlusion of the bilateral carotid arteries in the rat-temporal profile of cerebral blood flow (CBF), oligodendroglia and myelin]. No To Shinkei 49, 639-644.

Ullian, E. M., Sapperstein, S. K., Christopherson, K. S., and Barres, B. A. (2001). Control of synapse number by glia. Science 291, 657-661. doi: 10.1126/science. 291.5504.657

Vafabakhsh, R., Levitz, J., and Isacoff, E. Y. (2015). Conformational dynamics of a class C G-protein-coupled receptor. Nature 524, 497-501. doi: 10.1038/ nature 14679

Verderio, C. (2013). Extracellular membrane microvesicles and nanotubes in the brain: understanding their nature, their function in cell-to-cell communication, their role in transcellular spreading of pathological agents and their therapeutic potential. Front. Physiol. 4:163. doi: 10.3389/fphys.2013.00163

Verite, J., Janet, T., Chassaing, D., Fauconneau, B., Rabeony, H., and Page, G. (2018). Longitudinal chemokine profile expression in a blood-brain barrier model from Alzheimer transgenic versus wild-type mice. J. Neuroinflammation 15:182. doi: 10.1186/s12974-018-1220-7

Vermeiren, C., Hemptinne, I., Vanhoutte, N., Tilleux, S., Maloteaux, J. M., and Hermans, E. (2006). Loss of metabotropic glutamate receptor-mediated regulation of glutamate transport in chemically activated astrocytes in a rat model of amyotrophic lateral sclerosis. J. Neurochem. 96, 719-731. doi: 10.1111/ j.1471-4159.2005.03577.x

Vermeiren, C., Najimi, M., Vanhoutte, N., Tilleux, S., de Hemptinne, I., Maloteaux, J. M., et al. (2005). Acute up-regulation of glutamate uptake mediated by mGluR5a in reactive astrocytes. J. Neurochem. 94, 405-416. doi: 10.1111/j.14714159.2005.03216.x

Vernon, A. C., Smith, E. J., Stevanato, L., and Modo, M. (2011). Selective activation of metabotropic glutamate receptor 7 induces inhibition of cellular proliferation and promotes astrocyte differentiation of ventral mesencephalon human neural stem/progenitor cells. Neurochem. Int. 59, 421-431. doi: 10.1016/j.neuint.2011. 04.001

Wang, J. W., Wang, H. D., Cong, Z. X., Zhang, X. S., Zhou, X. M., and Zhang, D. D. (2013). Activation of metabotropic glutamate receptor 5 reduces the secondary brain injury after traumatic brain injury in rats. Biochem. Biophys. Res. Commun. 430, 1016-1021. doi: 10.1016/j.bbrc.2012. 12.046

Werner, P., Pitt, D., and Raine, C. S. (2001). Multiple sclerosis: altered glutamate homeostasis in lesions correlates with oligodendrocyte and axonal damage. Ann. Neurol. 50, 169-180. doi: 10.1002/ana.1077

Wilkinson, B. L., and Landreth, G. E. (2006). The microglial NADPH oxidase complex as a source of oxidative stress in Alzheimer's disease. J. Neuroinflammation 3:30. doi: 10.1186/1742-2094-3-30

Xue, F., Stoica, B. A., Hanscom, M., Kabadi, S. V., and Faden, A. I. (2014). Positive allosteric modulators (PAMs) of metabotropic glutamate receptor 5 (mGluR5) attenuate microglial activation. CNS Neurol. Disord. Drug Targets 13, 558-566. doi: $10.2174 / 18715273113126660199$ 
Yang, L., Mao, L., Chen, H., Catavsan, M., Kozinn, J., Arora, A., et al. (2006). A signaling mechanism from $G$ alpha q-protein-coupled metabotropic glutamate receptors to gene expression: role of the c-Jun $\mathrm{N}$-terminal kinase pathway. J. Neurosci. 26, 971-980. doi: 10.1523/JNEUROSCI.4423-05.2006

Yang, P., Zhang, J., Zhao, L., Jiao, Q., Jin, H., Xiao, X., et al. (2012). Developmental distribution pattern of metabotropic glutamate receptor 5 in prenatal human hippocampus. Neurosci. Bull. 28, 704-714. doi: 10.1007/s12264-0121286-7

Yao, H. H., Ding, J. H., Zhou, F., Wang, F., Hu, L. F., Sun, T., et al. (2005) Enhancement of glutamate uptake mediates the neuroprotection exerted by activating group II or III metabotropic glutamate receptors on astrocytes. J. Neurochem. 92, 948-961. doi: 10.1111/j.1471-4159.2004.02937.x

Ye, X., Yu, L., Zuo, D., Zhang, L., Zu, J., Hu, J., et al. (2017). Activated mGluR5 protects BV2 cells against OGD/R induced cytotoxicity by modulating BDNFTrkB pathway. Neurosci. Lett. 654, 70-79. doi: 10.1016/j.neulet.2017.06.029

Yin, S., Noetzel, M. J., Johnson, K. A., Zamorano, R., Jalan-Sakrikar, N., Gregory, K. J., et al. (2014). Selective actions of novel allosteric modulators reveal functional heteromers of metabotropic glutamate receptors in the CNS. J. Neurosci. 34, 79-94. doi: 10.1523/JNEUROSCI.1129-13.2014

Zabel, M. K., and Kirsch, W. M. (2013). From development to dysfunction: microglia and the complement cascade in CNS homeostasis. Ageing Res. Rev. 12, 749-756. doi: 10.1016/j.arr.2013.02.001

Zhang, Z., Ma, W., Wang, L., Gong, H., Tian, Y., Zhang, J., et al. (2015). Activation of type 4 metabotropic glutamate receptor attenuates oxidative stress-induced death of neural stem cells with inhibition of JNK and p38
MAPK signaling. Stem Cells Dev. 24, 2709-2722. doi: 10.1089/scd.2015. 0067

Zhao, Z., Nelson, A. R., Betsholtz, C., and Zlokovic, B. V. (2015). Establishment and dysfunction of the blood-brain barrier. Cell 163, 1064-1078. doi: 10.1016/j. cell.2015.10.067

Zhou, F., Yao, H. H., Wu, J. Y., Yang, Y. J., Ding, J. H., Zhang, J., et al. (2006). Activation of Group II/III metabotropic glutamate receptors attenuates LPS-induced astroglial neurotoxicity via promoting glutamate uptake. J. Neurosci. Res. 84, 268-277. doi: 10.1002/jnr. 20897

Zipfel, G. J., Babcock, D. J., Lee, J. M., and Choi, D. W. (2000). Neuronal apoptosis after CNS injury: the roles of glutamate and calcium. J. Neurotrauma 17, 857-869. doi: 10.1089/neu.2000.17.857

Conflict of Interest Statement: The authors declare that the research was conducted in the absence of any commercial or financial relationships that could be construed as a potential conflict of interest.

Copyright (c) 2018 Spampinato, Copani, Nicoletti, Sortino and Caraci. This is an open-access article distributed under the terms of the Creative Commons Attribution License (CC BY). The use, distribution or reproduction in other forums is permitted, provided the original author(s) and the copyright owner(s) are credited and that the original publication in this journal is cited, in accordance with accepted academic practice. No use, distribution or reproduction is permitted which does not comply with these terms. 